their presence in the blood. Several years ago Dr. John Eliot Woodbridge claimed that he had succeeded in aborting the disease by the use of certain remedies in its earlier stages. In a paper read before the AuERICAN Medical Association in San Francisco, and again at its meeting in Baltimore recently, he fully explained the treatment, claiming that it was abortive and rapidly curative. In the discussions which followed the realing of papers upon the treatment of "Typhoid Fever in Children," much time was consumed in discussing the Brandt method, which was highly extolled, and only slight allusions were made to the Woodbridge method, and in terms not altogether complimentary. Having treated a number of cases of the disease during the past summer and autumn, and succeeded in aborting it, we have no hesitancy in adding our testimony to its superiority over all other methods.

Under the antiseptic and disinfectant method we have really but two periods to this formidable disease - first, a period of rapid reduction of temperature, and secondly, the period of convalescence. By destroying the germs early in the attack, and before the development of toxins, we at once abruptly interrupt its course and prevent complications so frequent when the disease has existed for any great length of time. Tympanites, when present, disappears, dry tongue and delirium are prevented, diarrhea ceases, pyrexia ceases by the tenth or twelfth day, and the patient at once enters upon a favorable convalescence. With mind wh clear and muscular strength preserved, he is enabled to leave his bed by the end of the second week, and solid food may be allowed him much earlier than under the old régime, because there are no ulcerations of the ileum to contraindicate its use.

We believe that these results are brought about by both intravascular and intestinal disinfection. It has long been known by physicians that intestinal disinfection is an important indication in the disease, and the difficulty heretofore has been to find a remerly or remedies to accomplish this, and at the same time prove harmless to the system.

Of the combination of remedies recommended in the Woodbridge treatment, it may be difficult to determine the precise rôle played by each. Purgatives were thought to be contraindicated in the disease formerly and in the new treatment they are indicated. Both the podophyllum and calomel fulfill important indications, the latter as a disinfectant and purgative, and the former aids in clearing out the alimentary canal, especially the colon, which is now regarded as the sewer of the system.

Bintz claims, that in its passage through the alimentary canal, the protochlorid of mercury is changed into the bichlorid, and the latter is now regarded as one of the most efficient disinfectants and germicides known to the profession. It is now believed that most, if not all, intestinal affections are caused by speecific germs, and we may thus understand how calomel gained such reputation in their treatment. From simple catarrh to the more grave affections of cholera and dysentery, it is regarded as superior perhaps to all other remedies.

The danger from hypercatharsis is not regarded, since the diarrhea will cease and the system immediately rally after destruction of the germs. We believe the carbonate of guaiacol to be the active agent in the destruction of the typhoid bacillus both in the intestinal canal and in the blood and tissues of the body.

It belongs to the phenol group and is the active principle of creosote. Chemically pure, guaincol is of offensive odor and burning taste, and an irritant. It is insoluble in the stomach. Combined with carbonic acid, it is innocuous and non-irritant, and it has been found to allay irritability of the stomach and prevent abnormal fermentation. Von Heyden found that after leaving the stomach, it was decomposed into carbonic acid and pure guaiacol in the intestines, and it is here that it exerts its proper medicinal effects.

We have observed under its use that the characteristic typhoid stools become more consistent and lose their offensive odor. The odor of creosote is detected now in both the urine and feces. The menthol, thymol and eucalyptol act as intravascular disinfectants, doubtless, as their odor is detected in the perspiration. Large draughts of sterilized cool water promote both diaphoresis and diuresis, by which poisons are eliminated from the blood. It is proper to speak of cases in which these remedies are sometimes not well tolerated, when given in their regular routine. An irritable stomach will sometimes reject formulas 1 and 2 .

By the use of sinapisms, and the substitution of guaiacol carbonate, alone, in 5 to 10 grain doses every three to four hours, for from twenty-four to thirty-six hours, we have been enabled to control the irritability and return to the above formulas. Ptyalism will sometimes supervene upon the use of the mercury and we will be obliged to withdraw it. The guaiacol is now to be given, and the simpler aperients, as Hunyadi water as recommended by the author. We may not be able to abort the disease as early with these complications, but its course is still very much shortened and sequele prevented. It is superior to the Brandt treatment, because the latter will not abort the disease or prevent serious complications.

\title{
RESEARCHES ON RAPID PHOTOGRAPHY BY MEANS OF EDISON'S KINETOGRAPH AND THE ANIMATED REPRODUC-
} TION WITH THE KINETOSCOPE.

SHOWING ALSO BY THIS METHOD THE PRESENT AND FUTURE POSSIBILLITIES OF TAKING AND RE-PRODUCING CERTAIN ANIMATED PHYSIOLOGIC MOVEMENTS AS THE LARYNX, HEART, INTESTINES, ETC., AND CERTAIN DISEASES HAVING VISIBLE SYMPTOMS, ETC. WITH A HISTORIC REVIEW OF FIFTY YEARS OF PHOTOGRAPHY.

Read before the French Academy of Medicine, Paris, February, 1895, and in the Section on Physiology and Dietetics, at the Forty'sixtl

Annual Meeting of the American Medical Association, at Baltimore. Md.

BY J. MOUNT BLEYER, M.D., F.R.A.M.S. Fellow of the Royal Academy of Medicine aud Surgery, Naples. Italy; Corresponding Member to the Mexican Academy of Medicine; Cor. Corresponding Member to the Mexican Academy of Medicine; Cor
responting Member Socićt D'Electro-chérapie. France: Memresponding Member Societ
ber Electrical Association of New York; Merbber American Electrical Association of New York; M Mernber Ameri-
Medical Association: Member of the French Laryngological Society, Paris, France. NEW YORK.

This preliminary paper which I have the honor to present to you, gives mine and other experimental work with the kinetograph, kinetoscope and phonograph. Here, I wish to show the practicability of rapid photography by means of the kinetograph and the rapid reproduction of these photographs after their preparation herein described for the kinetoscope, by this means giving life to each and every possible mo- 
tion. This mechanical aid gives us the power to pho- a part of M. Arago's speech, that Daguerre's processes tograph and reproduce every possible physiologic proved to be so much more rapid and perfect than phase capable of visible movements, and in certain those Niepce was using that in the latter part of 1837 pathologic conditions showing their special visible/an agreement was signed between the two partners symptoms. Not only can the utility of this instru- permitting the name Daguerre to be associated with ment be applied in our science, but also to all others. the discovery, and it was many years before the small It is my hope in submitting this communication to " $\mathrm{d}$ " headed the word daguerreotype.

your critical judgment that what follows herein will $\mathrm{Cp}_{\mathrm{p}}$ to the time of Arago's explanation public curgive a satisfactory proof of the possibilities for iosity had for a year or more been awakened by further development and use in this field of study; accounts of the wonderful pictures, and some of the also that it prove as useful to others, as it has done pictures have been shown. Baron von Humboldt, in these researches made up to this date.

\section{GENERAL REVIEW OF FIFTY YEARSOF PHOTOGRAPHy.}

Taking a survey backward of fifty years of photography and contrast this with the possibilities of to-day, when in the darkest of the dark caves or cellars, or on the blackest of nights, the tyro photographer, armed with his little camera, and pistol loaded with magnesium cartridge, can obtain a picture full of vigor and marvelous in detail. This chasm has been bridged over in the fifty years since Daguerre gave before the French Academy of Sciences the secret of his wonderful process. The journey down the photographic history of those fifty years is full of wonderful struggles of mind over matter, strange hopes awakened, magical discoveries set aside, fascinating theories exploded, practical inventions pushing to the front, large areas covered, and more and more individuals of both sexes benefited by this discovery of the progressive scene painter, until to-day hundreds of thousands contribute to our knowledge and happiness in the practice of photography whilst gaining their daily bread.

The story of Daguerre's struggles and victory may well be told at this time, after a lapse of little over fifty years since his grand discovery. It was on the 19th of August 1839, that Arago, the noted French astronomer, before crowded halls and courts, gave the practical details of the process for fixing upon a prepared plate the images of the camera-obscura, and the France, by giving an annual stipend to Daguerre and the his associate, M. Isidore Niepce, provided that all their compatriots should be free to practice the new art. Arago's speech is even now most entertaining reading and should be familiar to all votaries of the art of photography, but we must content ourselves with little more than a review of some of the points which may indicate the appreciation in which the discovery was held at the time, and the prophetic insight that saw how full of value to science as well as art this great invention would prove to be. M. Arago dealt with the scientific problems of optics and chemistry involved in the search, showing the length of time after the knowledge that nitrate of silver blackened in the light before any successful experiments were made to fix the images of the camera by its use. He paid a tribute to the memory of M. Joseph Nicephore Niepce, describing the process by which, after three days exposure, he had succeeded in forming an image which could be retained on the plate. Such a process could of course only serve for copying engravings or drawings, and was impracticable for landscape, architecture or portraiture.

By an accident a meeting was brought about between Daguerre and Niepce, and a partnership formed, which ended only with the death of Niepce in 1833, after which time his son Isidore continued the re- held its sway until 1851, but soon after that time was
searches. Here it may be well to say, though it is not 
this latter soon having the field all to itself. We can inclirect connection with the art. But the story is too not permit ourselves to enter into the respective merits long to tell how and when photo-lithography, photoof processes, yet there are four great divisions, or per- graphing on blocks of wood for engravers, and the haps we may say three great divisions and one small various uses to which photography is now put, were one, which it is well to bear in mind in reviewing the first employed. Little by little it las traveled the last fifty years. These wonld be the daguerreotype world over, educating and delighting everywhere. from 1839 to 1851 : the albumin process on glass plates When we try to note the spread of this art. we are made practicably in 1849 , but soon, in 1851, set aside astonished at the uses to which it is now put. How by the collodion process, and fourth, the great popu- active the human brain is still in invention the thick larizer of photography, the gelatin bromid dry plate octavo volume published each year by the Pntent in 1871.

Previously to all this history of fifty years review there is to be found the published record of a discovery by Fabricius in $1 \tilde{\partial} 36$ when seeking the elixir which was to restore youth. He threw some sea salt into nitrate of silver, and noted that the chlorid of silver precipitated, though of a white color, became black as ink by exposure to sunlight. But this knowledge does not seem to have been utilized until Scheele in 1777 rediscovered the fact, and a few years afterwarl Professor Charles, the inventor of the hydrogen gas balloon, spread the chlorid of silver on paper, and placing the head of one of his pupils in a beam of sunlight, saw that the shaded portion remained clear, while the rest of the paper rapidly darkened. Still there was no chemic substance known that would retain the image, so, unless the sheet were put away in a dark place, the whole of it would soon blacken. It might be looked at from time to time in a subdued light or by artificial, or the silhouette thus formed could immediately be cut out and the perfect profile thus saved. The long sought compound by hyposulphite of sola, was invented in 1799 , but it was not until twenty years later that Herschel found its power of dissolving haloid salt of silver. Three other chemicals. chlorin, iodin and bromin, were discovered respectively in 1774,1811 and 1826 , so that we find the materials ready only a little while before the final discovery of their marvelous powers. One of the first of illustrated works in which photography was employed was Mr. Fox Talbut's "The Pencil of Nature:" though in 1840, among holiday books advertised as suitable for presents is one in beautiful binding, "Excursions Daguerriennes." Only a few years past over from that period and a need for orthochromatic photography was felt, especially in the use of medicine, etc., and researches were made to that end which have now borm fruit, though the new plates are still far from perfect. All through those years we note the patient search for the power not only to translate the image into black and white, but to retain the gradation of color so beautifully pictured on the ground glass in the camera. Office containing only patents bearing upon photography, improvements in cameras, shutters, tripods, etc. testifies. Many hundreds of books have been written upon the history of photography and its practice in every direction. Last year's Annual gives the titles of forty-four added to the list. Tnere are over sixty periodicals, appenring in different countries, some weekly, others monthly, a few semi-monthly. Of societies the list gives in America 54, and in foreign countries 107. Even in Japan there is a periodical devoted entirely to photographic matters, called Srsth in shimpar. It is a monthly and sells for 15 sen, or about 12 cents.

The facility with which the prepared plates can be manipulated, the ease with which hundreds of the new celluloid films can be carried about, the quality they possess of retaining their sensitiveness for months, the fact that exposures may be made in Central Africa or in the neighborhood of the north pole, and the image not developed until the traveler returns to his comfortable laboratory at home, are all magical advances in the fifty years since Daguerre told his secret. What the next half-century will do with the subtle powers of the sensitive plate remains to be seen. To artists familiar with the study of color any hope that the gradations of hues shall be retained by a negative image and communicated to a positive print seems absurd. Constant progress is being made toward the bettering of the interpretation of color values. The mysteries of chemistry are being tested: chlorophyl, eosin, erythrosin and other new compounds are being employed. Bright, thoughtful, intelligent men are reaching into the unknown world of light and chemistry, experimenting and recording with scientific accuracy the story of their researches. The difficulty consists in obtaining gradations of black and white corresponding to the luminosity of the colors of nature. In copying paintings this is especially desirable, and already a great advance has been made. Even the amateur finds in the market prepared plates with which he can produce results in which equivalent gradations of tones stand

A hinocular camera was invented by Sir David for the various tints of color. These plates are called Brewster for taking pictures for use in Professor orthochromatic (right color). Experiments in this Wheatstone's new stereoscope. Lenses of similar direction will continue until the full beauty of the power were placed side by side, distanced by the aver- image of the camera will be kept in so far that our age measurement between the eyes. This was in reds will no longer be coal-black, our blues not faded 1849. We must remember that up to that year paper or white, and our bright yellows dull and gloomy. and the silvered metal were the grounds sensitized for Experiment in photographing an orange by the ordiuse in the camera. Then came the use of albumin nary and by the orthochromatic plate will show the spread upon glass so that it would hold the material advantage of using the latter.

used to sensitize the paper in the calotype process. This avoided the grain of the paper and gave a more perfect picture.

In the United States it was estimated that there were ten thousand daguerreotypists by 1850 , and some five thousand workmen who were engaged in the manufacture and sale of plates, cases, chemicals and apparatus, or in other ways receiving their support from

Bearing upon this point comes the latest news, that the modern theory of color sensation due to the excitement of the three sets of nerve fibrils is put to service by Mr. F. E. Ives. He, the account says, "produces simultaneously three negatives from three differently prepared plates by light passed through three screens of various colors, his object being to produce negatives each representing the intensity with 
which light affects one of the set of nerve fibrils in the eye. Lantern pictures are made from these negratives, and projected on a screen by a triple lantern. One picture passed through a red that affects only the fibrils excited by red, one through a similar green, and one through a suitable violet, the result being a representation of the landscape or object photographed in its true colors." Mr. Ives has published a book dealing with this subject, which he calls "A New Principle in Helichromy."

Against the clumsy apparatus of the first daguerreotypists we can set an array of cameras of most perfect mechanical construction. each fitted with some special contrivance endearing it to its inventor, and possibly to others. We find the colossal structures in use in certain galleries, and the popular so-called "detectives," the inconspicuous vest camera, or still smaller ingeniously contrived hoxes for photographic. purposes. To the advance in the construction of lenses, and to improvements in the shapes and principles of cameras, is due, as well to improved chemic processes, the quality of late photographic work. It is interesting to learn why the lenses in existence at the time of the invention of the daguerreotype could not do the work they were called upon to perform. The lenses constructed for use in the telescope and microscope embraced too small a field, including only at most a few degrees, while that for the camera frequently now embraces ninety degrees when employed for landscape work. The portrait lens needed a much smaller field, twenty or thirty degrees being enough, but required to be so large as to let plenty of light through it, and thus reduce the time of sitting. Many were the defects in the early time due to badly constructed lenses. The fifty years have brought improvements of inestimable advantage, and the variety and quality of the lenses now in the market show the progress of the optician's art.

One of the latest improvements, for which the tour ist must be very grateful, is the use which has been made of celluloid, on which, instead of glass is spread the sensitive film. One firm called these plates "ivory films." Where once the traveler burdened himself with boxes of heavy glass, he may carry to-day twelve dozen "films" for each box of one dozen glass plates. Stripping films or gelatin and the sensitive emulsion on rolls of yaper are admirable for the traveler. It is needless to dwell on the value photography has in corroborating the statement of the tourist who returns from a strange and little-known country. M. Le Plongeon told me of the incredulity with which his friends regarded the drawings which he brought back from his first visit to Central America. Any artist of an inventive turn could have made such pencilings. Not so with the photographs taken during his second visit. The statements of the camera were accepted, their authenticity undoubted. However untrained in drawing, the author may now gather material for illustrating his writings as he journeys up and down the land, for from the lightning express even he may make his "snap shot," feeling quite certain he has a valuable record, which the trained artist can "work up" for him.

The uses to which photography is being put this year can hardly be told. Its value in illustration is well known to all. Here it has helped to popularize artistic work, and cheapen the cost of its production to a surprising extent. Now but a few hours need pass before the thought of the artist is made the joy of the reader, drawing, photographic copy, relief plate, and printing following one another with nineteenth century speed. From the coarse outline of the newspaper "cut" to the wonderful reproduction of paintings by the photogravure process we mount on stepping stones of victorious achievements in photography, made to serve with reliable accuracy the common and the elevated, the political cartoon and the édition de luxe. The reproductions in color of the works of aquarellists are imitatively deceptive, and their educational influence of incalculable value.

We must not pass over the scientific value of $\mathbf{M r}$. Maybridge's publications on the action of man and the lower animals, or "The Horse in Motion." Upon these records, however absurd and laughable some may be, we must base our knowledge, intelligently using it for artistic purposes. It is well known that the camera can tell us what it sees when the plate is exposed but one two-thousandth part of a second, whilst the human eye can open and shut in about the one-tenth part of a second. We can not, then, say that photography is true for us when it pictures the rapidly revolving wheel as if it were motionless. If an artist paints the spokes, the wheel does not appear to go round; if he paints the blurred effect of the whirling wheel, we accept it as a representation of speed. There are photographic and optical as there are microscopic and optical truths. We do not paint a drop of blood as it looks through the microscope, but as it appears to our eyes. From the unquestioned statement of fact as concerming the action of animals we must train our eyes to see better the combination of position of hody and action of limbs, and determine how far old methods are good, though false, and how far the new scientific truths must force us to change the ordinarily accepted and conventionalized forms.

The uses to which science has put photography are very numerous, from records of the infinitely little to the infinitely great; from microscopy, which deals with the invisible, to the vastness of astronomic wonders. The latest contributions to our knowledge of the sun, moon and stars, made by photographs taken by the aid of the powerful telescope at the Lick Observatory, strongly contrast with the researches. into the invisible world of nature revealed through the microscope. Dr. Draper made the first daguerreotype of the moon in 1840; Foucault, of Paris, first succeeded in making a picture of the sun in 1845: and it was $18 \tilde{5} 0$ before Professor Bond, of Harvard College, made the first daguerreotype of a star. In 1851 Dr. Busch, of Königsherg, photographed a solar eclipse. Two scientists, Professor Schuster and $\mathrm{Mr}$. Lockyer, in 1862 obtained a photograph of the spectrum of the eclipsed sun. In 1881 Dr. Henry Draper had successfully photograped a nebula, and later the spectrum of a star. Even the aurora borealis has been photographed in 1889 .

In connection with the study of spectrum analysis, photography has played a most important part, for it has recorded lines not visible to the naked eye-lines. revealed only by the photograph in that part of the spectrum in the violet and lavender regions, and even beyond, where all is dark to us. In the study of stars. by this procedure we learn how some are like our sun, others glowing masses of matter just beginning to burn, and still others nearly burnt out, like Arcturus and Aldebaran. We marvel, when we think how feeble seems the light of the stars, to learm that only as much 
light as can come through a slit one three-hundred and fiftieth of an inch is permitted to affect the sensitive plate. Again, the movements of the earth would in the two hours required to form an image soon carry the light off the plate were there not ingenious mechanical apparatus by which the image is always kept at the same place on the plate. And now photography is not only used for mapping out the known heavens, but the camera reveals to us the presence of stars which the human eye has not seen. For many years Miss Maria Mitchell and her assistants have photographed the ever-changing sun spots. Astronomers from all over the world have met in Paris and arranged a plan for using photography to obtain a picture of the entire heavens. Cameras will be set up in numbers of observatories in many countries, and many negatives made of the entire contents of the universe. It is proposed to catalogue two millions of the brightest stars and note their position with great precision, as until such maps exist many other astronomic problems can not be solved. We know, for instance, that our sun with its planetary system is voyaging through space. These charts will help determine the route and circumstances of the journey.

Dr. Galton's composite photography has been too th well described to claim more than a word in recognition of an attempt to put photography to a scientific use. In this country Professor Stoddard, of Smith College, has made many interesting studies and published several articles upon the subject, and Dr. Noyes, in two pictures of the insane, gives composite types showing expressions that perpetuate themselves in individuals during mental disease.

Photography enables publishers to duplicate in little valuable works and store away small negatives of large folios or manuscripts during the process of publication. Trade uses photography to picture its new furniture, gas fixtures, china, etc., reproducing thus objects too bulky for the "drummer" to carry about with him. Instead of the slow process of copying by hand the geometric designs furnished by the kaleidoscope, numberless changes can be readily photographed in a short time, and furnish suggestive material from which to work. The wall-paper manufacturer uses photography to reduce or enlarge patterns; the delicate figures on watch faces can now be made by its use. These watch dials have been painted by hand at a cost of a dollar each. Now, it is said, a photographic process has been purchased by a watch company by which these dials can be made at the slight expense of ten cents each, electric light serving as well as daylight for their manufacture. Even the quality of steel has been tested by photographic examination. The microscope shows steel to be composed of an agglomeration of crystals, by the difference in which its quality may be determined. The piece of steel to be examined at a certain foundry was heated until it was white, when it was photographed, and the resulting negative examined by the microscope. Those little toy pictures in watch charms have to be made by the aid of the microscope; it is said that only one man in New York can do such work. Even fraud can be proved by the use of the camera. A Berlin merchant was detected in crooked ways, and illegitimate after-entries of a number of his accounts were shown by photography. Blue inks appear much lighter than brown. A chemic test destroys the original, but the faithful plate leaves it intact whilst telling the story of the fraud.
In war photography has been used since the English made pictures in the Crimea. Balloon photography has become quite an art. Balloons are said to be perfectly safe from rifle or artillery fire if 700 yards above the ground. Electricity is made to play its part in exposing the plate in the camera attached to the balloon. During the Franco-Prussian war and the siege of Paris small photographic copies of valuable documents and daily papers were made and rolled into quills, which were fastened to carrier pigeons, and thus taken to their destination without the lines. The Eiffel Tower in Paris has been offered Professor Marey to enable him to make studies in photography of birds in flight, and very instructive results are anticipated. Many will remember the picture of the experiment at Willett's Point when the donkey's head was blown off by the use of dynamite, but the picture was taken before the body fell.

The late Mr. Baden Pritchard, whose work in the Woolwich laboratory made him famous, conceived the very valuable as well as feasible idea of reducing the map of a country on little gelatin films so small that fifty or more could easily lie in the top of a field case. They could readily be employed and clearly read by the aid of a magnifier. To render them very serviceable they were tanned so as to be waterproof. In the English army a photographic wagon is used which is fitted up with two cameras and several lenses, so as to make plates of different sizes or for varied purposes. One of the outfits is so contrived as to be readily packed on a mule. Bromid paper and material for making platinotypes are also carried. Both in our army and navy photographic outfits are furnished and some of our officers have become very expert. Photography may be applied to surveying, as Lieutenant Reed, of the United States Army, has described. It may also serve for studies in meteorology. Photographing rifle bullets and cannon-balls in motion has become an everyday matter, but a novel experiment is said to have been made not long since in Berlin by Professor Treeson, who arranged within a cannon-ball a sort of camera which recorded the character of its flight. A tiny pin-hole admitted light, and a sensitive plate within the ball recorded the twists and turns of the projectile in its passage through the air. The gun was fired point-blank at the sun, which sent a beam upon the plate, recording itself as a point, but as the ball swerved more away from the sun a spiral line was formed and marked upon the plate.

In Germany there are many photographic schools, and in one establishment in the midst of very beautiful scenery in the Bavarian Alps more than one hundred pupils have been educated. Last year there was a summer school of photography at Chautauqua and lectures are given each winter at Columbia College. The result of such systematic study ought eventually to advance the art, though at present the students deal principally with practical and scientific problems. At the Cooper Institute and Young Women's Christian Association, in New York, students are trained to skilfully retouch negatives, and thus photography helps a large class in obtaining a livelihood.

There is a side of the practice of photography which humanitarians will welcome. It has been suggested that the camera be used as a substitute for the gun, and pictures rather than corpses be bagged. In all seriousness the suggestion is well worthy of consideration, for the health-giving tramp and the difficulty of the sport are equal in both cases. There 
would be a test of the veracity of the sportsman that In the quiet of one's study one may consult details of would doubtless advance the unorals of the hunting Moorish intricacy of design, the stately temples of fraternity. To the fisherman the camera might be val- Greece, or the strange gargoyles of a Gothic cathedral. uable to chronicle the marvelous size or number of Reproductive processes have cheapened the cost withthe day's catch, even if it could not quite take the out lessening the value of these pictures, so that the place of $\mathrm{Ik}$ Walton's favorite sport. The naturalist student may store away treasures in their portfolios. might gain much information of the habits of wild Even in more practical ways the blue print is made to birds and game from the sportsman's album at the duplicate the design of the architect, and enable him end of a season.

There is one service to which photography has been profitably applied which demands consideration, and as it is practiced most effectively in France, it may be well to make a few notes of the photographic establishment at the Prefecture of Police in Paris. Here there is a system of picturing criminals which in connection with another system of measurement, makes it easily possible to identify them. Head, ear, index finger, waist, foot, and the height of the whole figure, as well as the breadth of the extended arms are carefully measured and recorded, as are also any distinctive birth marks, moles, scars, etc. Then the prisoner is taken to well-lighted galleries in the upper story of the building, where pictures of the face in front view and profile, of half and full figure, are made. Since the late improvements in rapid plates it is possible to obtain these pictures even when the subject is refractory. By the use of artificial light 20,000 pic-
tures the size of postage stamps can be made in a single night, and sent broadcast over the country to the police force. There are said to be over 100,000 photographs of different criminals, 40,000 of this number being of women and children. These pictures are now, by the assistance of the classified measurements, so arranged that it is an affair of but little time to determine whether the new comer has ever been in the clutches of the law or not; and if he has, to fix upon him his past crimes and punishments. Modern police the world over have found photography of great assistance, but the systematic care shown by the French might profitably be employed everywhere. The law recognizes the authoritative testimony of photography and often employs it. Photography for the purpose of identification is not necessarily confined to the criminal class. It was employed in 1876 on the season tickets of exhibitors at the Centennial
Exhibition at Philadelphia. Another way in which Exhibition at Philadelphia. Another way in which
it is serviceable is in reproducing in small size, so that they can be mailed ummounted, the newly finished oil paintings of artists, who may thus reach patrons and show the subject of the new work. Art dealers in America are constantly receiving such photographic notes from European correspondents, and familiar with the general character of workmanship, they can readily determine whether they wish to order or not. Sometimes notes of color accompany the photograph.

Artificial light in the practice of photography has long been found serviceable. The burning of magnesium wire and the electric light furnished sufficient illumination under full control. Within the past two years various compounds have been put upon the market which have popularized the taking of pictures by night, either using fulminating compositions or employing the alcohol lamp and the dry powdered magnesium.

Early in the history of photography its service to architecture was discovered. To-day it brings to every student authentic records of the past, the story of every age, from the lintel architecture of far-away Egypt to the primitive log hut of the Western settler.

by a little outlay of time and money to give his patrons a copy of his own elaborate work. So, too, may the architect keep informed of the progress of buildings being constructed in distant places away from his office, from plans he has made. Careful photographs taken frequently will show every stage of the work, and avoid many journeys which would otherwise be necessary. By this means our government is able to control from the central office the payments for work done in foreign lands. Engineers also employ photography for a similar purpose.

Philip Gilbert Hamerton may be quoted as an appreciator of photography when he writes in one of his thoughtful essays on landscape: "Instantaneous photography is not so valuable for stormy seas in sunshine as in dull weather, because it confounds foam and glitter, but the fidelity with which it renders minor waves is quite beyond all human rivalry. The excellent photographs of yachts in motion which are now so common, contain endless and most authentic; information about all kinds of minor waves and ripples. A collection of them is even better than nature itself, so far as form only is concerned, for no memory can retain the natural form with any approach to photographic accuracy. Painters make constant use of these invaluable memoranda, and by their help, and the education they give to the eye in preparing it to see nature itself, a greatly increased veracity in the drawing of water has penetrated even our current newspaper illustrations."

One can not close even so incomplete a review as this of the first half-century of photography without a reference to the position it holds with regard to art. Though it would require a long essay to deal with the subject as it merits treatment, it is important to make certain confessions of blighted hopes, and at the same time to look with tempered enthusiasm into the future. As an aid to science, as a recorder, as a duplicator, photography has helped advance civilization. Of itself it has failed to occupy the place it may yet hold as a means for expressing original thought of a fine order. With its recognized qualities and in the hands of a thoroughly trained worker perfectly familiar with the laws of chemistry and optics, and with artistio feeling and training, it may be placed on a plane where its beauties will foree from all acknowledgment that it has powers which rank it as one of the finest of the graphic arts.

II.- THE EXPERIMENTAL RESEARCHES ON RAPID PHOTOGRAPHY BY MEANS OF THE KINETOGRAPH AND KINETOSCOPE, ETC.

To our Edison, in the year 1887, the notion presented itself that it was possible to devise an instrument which should do for the eye what the inimitable phonograph does for the ear, and that by a combination of the two, all motion and sound could be recorded and reproduced simultaneously. This idea, the germ of which came from the little toy called the zoetrope, and the former combined work of Maybridge, Marie and others has now been accomplished, so that 
every change of facial expression and any other visible movement can be recorded and reproduced life size. The kinetoscope and kinetograph of to-day's construction is only a small model illustrating the future possibilities and its present stage of progress. With each succeeding month new changes are brought into view. It can already be forecasted from reached.

what has been done, that in a very short time these works of Edison, Dickson, Maybridge, Marie and others who will enter in this field of investigation will be crowned with successes heretofore unknown. These already explored fields bring us to recognize the known and future contingencies of being able to reproduce the many thousands of varieties of motions and expressions known to us in medicine, either as physiologic or as symptomologic in a variety of diseases. Its usefulness does not stop here by any means. The arts in all their branches claim its services also.

The synchronous attachment of rapid photography with the phonograph was one of the early thoughts of this inventor, in order to record and give back impressions to the eye as well as to the ear. The comprehensive term for this invention is the kinetophonograph. The dual talking machine is the phono-kinetograph and the reproducing-machine the phono-kinetoscope, in contra-distinction to the kinetograph and the kinetoscope, which relate respectively to the taking and reproducing of movable but soundless objects. The initial experiments took the form of microscopic pin-point photographs, placed on a cylindrical shell corresponding in size to the ordinary phonograph cylinder. These two cylinders were then placed side by side on a shaft, and the sound record was taken as near as posible synchronously with the photographic image impressed on the sensitive surface of the shell. The photographic portion of the undertaking was seriously hampered by the defects of the materials at hand, which, however excellent in themselves, offered no substance sufficiently sensitive. How to secure clear-cut outlines, or indeed any outlines at all, together with phenomenal speed, was the problem before him which puzzled. The Daguerre, albumin and kindred processes met the first requirements, but failed when subjected to the test of speed. These methods were therefore regretfully abandoned, a certain precipitate of knowledge being retained, and a bold leap was made to the Maddox gelatin bromid of silver emulsion, with which the cylinders were coated. This process gave rise to a new and serious difficulty. The bromid of silver haloids, held in suspension with the emulsion, showed themselves in an exaggerated coarseness when it became a question of enlarging the pin-point photographs to the dignity of one-eighth of an inch, projecting them upon a screen, or viewing them through a binocular microscope. Each accession of size augmented the difficulty, and it was resolved to abandon that line of experiment and to revolutionize the whole nature of the proceedings by discarding these small photographs, and substituting a series of very much larger impressions affixed to the outer edge of a swiftly rotating wheel, or disk, and supplied with a number of pins, so arranged as to project under the center of each picture. On the rear of the disk, upon a stand, was placed a Geissler tube, connected with an induction coil, the primary wire of which, operated by the pins, produced a rupture of the primary current, which in its turn, through the medium of the secondary cur- rent, lighted up the Geissler tube at the precise moment when a picture crossed its range of view. This electric discharge was performed in such an inappreciable fraction of time, the succession of pictures was so rapid, and the whole mechanism so nearly perfect, that the goal of the inventor seemed almost

(To be continued.)

\section{MEDICAL PRACTICE ACTS.}

PRACTICE OF MEDICINE IN RHODE ISLAND.

A law was passed in Rhode Island in 1895 making it the duty of each town and city clerk to keep a "Medical Register," one full page thereof to be set apart for the registration of each physician in his town or city. When any physician shall die or remove from the city or town, the clerk is to make a note of same at the bottom of the page. On the first day of January in each year he is to transmit to the State board of health a duly certified list of the registered physicians. His fee for registration is fifty cents. Following this, it is made unlawful for any person to practice medicine or surgery in any of its branches, within the limits of the State, who has not exhibited and registered in the city or town clerk's office of the city or town in which he or she resides, his or her authority for so practicing medicine, as prescribed, together with his or her age, address, place of birth and the school or system of medicine to which he or she proposes to belong; and the person so registering shall subscribe and verify by oath, before such clerk, an affidavit containing such facts, which if willfully false, shall subject the affiant to conviction and punishment for perjury. Authority to practice medicine under this law shall be a certificate from the State board of health. The board is, upon application, to issue a certificate to any reputable physician practicing or who desires to begin the practice of medicine or surgery in the State, who possesses any of the following qualifications: 1. A diploma from a reputable and legally chartered medical college, endorsed as such by the State board of health; 2 . Satisfactory evidence from the person claiming the same that such person was reputably and honorably engaged in the practice of medicine or surgery in the State prior to Janurary 1, 1892. Any person not qualified as so provided, before practicing shall present himself before the State board of health and submit himself to such examination as the board may require. The board shall examine any person presenting himself and if the examination is satisfactory shall issue its certificate. Fee for examination is $\$ 10$. Applicants may present their credentials by mail or by proxy. Not more than $\$ 2$ shall be charged for any certificate. Nothing in this law shall be so construed as to authorize any itinerant doctor to register or to practice medicine in any part of the State. The board may also refuse to issue its certificate to any individual guilty of grossly unprofessional conduct of a character likely to deceive or defraud the public, and it may after due notice and hearing revoke certificates for like cause, appeal in such cases being given to the supreme court. Nothing in this law shall be so construed as to discriminate against any particular school or system of medicine, or to prohibit women from practicing midwifery, or to prohibit gratuitous services in case of emergency; nor shall it apply to commissioned 